\section{Prevalence of Metabolic Syndrome in Patients with Rheumatoid Arthritis}

\section{Romatoid Artritli Hastalarda Metabolik Sendrom Prevalansı}

Banu MESCİ, Aytekin OĞUZ

2nd Department of Internal Medicine, Göztepe Training and Research Hospital, İstanbul, Turkey

\section{Dear Editor,}

We have read with great interest the study of Akbal et al. ${ }^{[1]}$ about the prevalence of metabolic syndrome in patients with rheumatoid arthritis. We believe that this study will be a significant contribution to the literature. However, we have some concerns about the study methods and evaluation of the findings.

It was stated that the control group enrolled in the study contained subjects who did not have inflammatory bowel disease. This is a poor description that fails to reflect the characteristics of the control group and doesn't clarify whether this population has other diseases or not. The authors have reported the prevalence of metabolic syndrome to be $16 \%$ in the control group with an average age of 49.8 years and gender distribution of $85.1 \%$ women. However, these findings do not match the data obtained from two large-scale epidemiological studies conducted in our country. The prevalence of metabolic syndrome among adult patients has been reported in two studies and the results are $37.1 \%$ in the TEKHARF study (Turkish Adult Risk Factor Survey) (in male patients $31.2 \%$, in female patients $42.8 \%)^{[2]}$ and $33.9 \%$ in the METSAR study (Metabolic Syndrome Prevalence Survey in Turkey) (in male patients 28\%, in female patients 39.6\%). The prevalence of metabolic syndrome is known to increase with age and to be higher in women. ${ }^{[3]}$ Consequently, it is obvious that the evaluation of the study should be radically changed to reflect that the prevalence of metabolic syndrome in patients with rheumatoid arthritis is much lower than that of the overall population!
In the article, a correlation was reported between the use of corticosteroids and fasting blood glucose level, but it wasn't clarified whether or not there was a difference between corticosteroid use and triglycerides. Increased blood glucose is among the metabolic effects of corticosteroids while the most important dyslipidemic effect of corticosteroids is the heightened level of triglycerides. ${ }^{[4,5]}$ It is possible to attribute the increased level of triglycerides to steroids used by $54.9 \%$ of the patients. Therefore, we believe that comparing a group of patients using corticosteroids to healthy individuals who do not use corticosteroids and attributing the findings like high levels of triglyceride and blood pressure (which are well-known side effects of steroids) to the disease or the degree of activity of the disease can be misleading.

\section{REFERENCES}

1. Akbal A, Selçuk B, Gürcan A, Kurtaran A, Ersöz M, Akyüz M. Metabolic syndrome in patients with rheumatoid arthritis. Turk J Rheumatol 2009;24:202-5.

2. Onat A, Hergenç G, Can G Prospective validation in identical Turkish cohort of two metabolic syndrome definitions for predicting cardiometabolic risk and selection of most appropriate definition. [Article in Turkish] Anadolu Kardiyol Derg 2007;7:29-34.

3. Kozan O, Oguz A, Abaci A, Erol C, Ongen Z, Temizhan $A$, et al. Prevalence of the metabolic syndrome among Turkish adults. Eur J Clin Nutr 2007;61:548-53.

4. Sholter DE, Armstrong PW. Adverse effects of corticosteroids on the cardiovascular system. Can J Cardiol 2000;16:505-11.

5. Clore JN, Thurby-Hay L. Glucocorticoid-induced hyperglycemia. Endocr Pract 2009;15:469-74.

Correspondence: Banu Mesci, M.D. Göztepe Eğitim ve Araştırma Hastanesi, 2. İç Hastalıkları Kliniği, 34722 Göztepe, İstanbul, Turkey. Tel: +90 216 - 5664000 e-mail: banualpaslan@gmail.com

\section{Author's response}

Dear Editor,

In response to the critique of our article, we would like to raise the following points. We did not say that "the control group enrolled in the study contained subjects who did not have inflammatory bowel disease."

The control group included those without rheumatoid arthritis (RA), Reiter disease, and ankylosing spondylitis and psoriatic arthritis and not only inflammatory bowel disease. In addition, arthritis 
can be seen in various diseases including vasculitic syndrome, systemic lupus erythematosus, Sjogren's syndrome, liver diseases, renal diseases and metabolic diseases. These were excluded from the study.

Actually, the prevalence of metabolic syndrome (MS) was lower in our cohort compared to other studies as the TEKHARF and METSAR. We did not claim an elevated prevalence of MetS in RA; in fact, there was no significant difference between the groups. The authors state that "the evaluation of the study should be radically changed to reflect that the prevalence of MetS in patients with RA is much lower than that of the overall population." However, we found that the prevalence of MetS in both the RA and control groups was lower compared to the overall population. In addition, several studies indicated the prevalence of MetS was lower than in the TEKHARF and METSAR. Gündoğan et al. ${ }^{[1]}$ demonstrated that the prevalence of MetS was 28.8\% (male, 23.1\%; female, $33.5 \%$ ) and Erem et al. ${ }^{[2]}$ reported that the prevalence of MetS was $26.9 \%$ (21.7\% in male, $31.3 \%$ in female). Consequently, our study population may not reflect the overall population. However, each study should be evaluated against its own control group.

"We did not evaluate the correlation between use of corticosteroids and fasting blood glucose levels and other metabolic parameters." We reevaluated the relationship between use of corticosteroids and metabolic parameters and found no significant correlation. In our study, we found only significant differences in glucose levels in patients using corticosteroids. There was no difference in TG, HDL$\mathrm{C}$, hypertension and waist circumference between subjects using and not using corticosteroids. Previous studies reported that long-term corticosteroid use may disturb metabolic parameters, but there have been few studies evaluating the relationship between MetS and RA. Toms et al. ${ }^{[3]}$ demonstrated that longterm exposure to medium doses of corticosteroid is associated with the increased prevalence of high triglycerides and hypertension, but not with any of the other components (low HDL, obesity, and glucose intolerance), or the presence of the MetS itself. In our study, patients receiving corticosteroids used a low dose (median corticosteroid dose was $7.0 \pm 4.7 \mathrm{mg} /$ day). Therefore we think that the metabolic changes were not due to the use of corticosteroids.

We observed significantly different prevalence rates of the MetS among different degrees of disease activity. Zonana-Nacach et al. ${ }^{[4]}$ found that in RA patients, MetS was related to pain and functional status suggesting disease activity in patients with RA. Karvounaris et al. ${ }^{[5]}$ demonstrated the correlation of RA disease activity with MetS. Similar to our results, this data suggests that RA disease activity correlates with MetS.

\section{REFERENCES}

1. Gündogan K, Bayram F, Capak M, Tanriverdi F, Karaman A, Ozturk A, et al. Prevalence of metabolic syndrome in the Mediterranean region of Turkey: evaluation of hypertension, diabetes mellitus, obesity, and dyslipidemia. Metab Syndr Relat Disord 2009;7:427-34.

2. Erem C, Hacihasanoglu A, Deger O, Topbaş M, Hosver I, Ersoz HO, et al. Prevalence of metabolic syndrome and associated risk factors among Turkish adults: Trabzon MetS study. Endocrine 2008;33:9-20.

3. Toms TE, Panoulas VF, John H, Douglas KM, Kitas GD. Methotrexate therapy associates with reduced prevalence of the metabolic syndrome in rheumatoid arthritis patients over the age of 60- more than just an antiinflammatory effect? A cross sectional study. Arthritis Res Ther 2009;11:R110.

4. Zonana-Nacach A, Santana-Sahagún E, JiménezBalderas FJ, Camargo-Coronel A. Prevalence and factors associated with metabolic syndrome in patients with rheumatoid arthritis and systemic lupus erythematosus. J Clin Rheumatol 2008;14:74-7.

5. Karvounaris SA, Sidiropoulos PI, Papadakis JA, Spanakis EK, Bertsias GK, Kritikos HD, et al. Metabolic syndrome is common among middle-to-older aged Mediterranean patients with rheumatoid arthritis and correlates with disease activity: a retrospective, cross-sectional, controlled, study. Ann Rheum Dis 2007;66:28-33.

Correspondence: Ayla Akbal, M.D. Ankara Meslek Hastalıkları Hastanesi, Fizik Tedavi ve Rehabilitasyon Kliniği, 06300 Keçiören, Ankara, Turkey Tel: +90 312 - 5808395 e-mail: ayla_yavuz@gmail.com 